\title{
A Study of the Roles of the Art Forms of Tang and Song Dynasties in the World Cultural Game
}

\author{
Xiaodong Yuan \\ Zhengzhou Institute of Aeronautical Industry Management \\ Zhengzhou, China
}

\begin{abstract}
In the last decade East-West cultural clash has been in a "static and gaming" state, which irreversibly exists in the post-crisis era. Meanwhile, various subjective and objective factors influencing the state begin to appear in the bustling world cultural game, leading to cultures of different nations as the "players" to break the "Nash equilibrium", as a result of which many Chinese people have been waken up to recall different crises with the cultural invasion. If Chinese art forms of Tang and Song dynasties has been the "balanced"identity and is listed in the cultural exchange strategy, then it is necessary today to make it to the forefront of the cultural game. But China's five-thousand-year cultural attribute determines our great united harmonious cultural pattern, seeking common ground while putting aside differences. Nowadays, with the opponents's unpredictable cultural strategy, we should take the initiative to delay our any strategic decision in the game. But we should not ignore the important roles of Chinese art of Tang and Song dynasties in Chinese cultural game.
\end{abstract}

Keywords-Chinese art of the Tang and Song dynasties; cultural game; strategyrds

\section{INTRODUCTION}

Today, in the early 21 st century, human civilization has reached unprecedented prosperity. And at the same time Chinese culture's rising again has undoubtedly accelerated the integration of the world and also intensified the unbalanced situation of the strategies in the world cultural game.

Up to now East-West cultural clash has been in a "static and gaming" state, which irreversibly exists in the post-crisis era. Meanwhile, various subjective and objective factors influencing the state begin to appear in the bustling world cultural game, leading to cultures of different nations as the "players" to break the "Nash equilibrium", as a result of which many Chinese people have been waken up to recall different crises with the cultural invasion. So no static point exists in the world cultural game and then it is not difficult for us to predict the lurking risks in the game. Also, there is no denying that opportunities also exist in the game. If the Chinese art form of the Tang and Song dynasties has been in the "balanced" identity and is listed in the cultural exchange strategy, then it is necessary today to make it to the forefront of the cultural game. But China's five-thousand-year cultural attribute determines our great united harmonious cultural pattern of seeking common ground while putting aside differences. Nowadays, with the opponents' unpredictable cultural strategies, we should take the initiative to delay our any strategic decision in the game to deter the gangsters and the like, which reveals the essence of the "perfect equilibrium theory" of shaking hands proposed by German scholar Reinhard Selten.

\section{The State of the Cultural Game under Global INTEGRATION}

Culture develops due to exchanges and dies to backwardness. The differences of regions and nations lead to various cultural attributes in religions, ethics, aesthetics, artistic creation, production and living and their different strategies in the cultural game.

With the rapid development of global integration, the conflict and competition between different cultures have reached the unprecedented fierce and brutal phase. And under the influence of the East-West cultural clash, many small countries and those that don't have profound cultural heritage together with the traditions and customs which have been handed down for thousands of years are beginning to decline and even die away. In Africa, Latin America, southeast Asia and some local cultures of the Arab world, some traditional cultures and customs with transcendental animism are hard to find today. These vivid examples tell us that there does not exist the concept of cooperative game in the fierce world cultural game. Even if there does, it is just like a flash in the pan. In the non-cooperative game, nations with the same or similar ideology as the "players" are trying to obtain the cultural rights and related interests that did not originally belong to them through all kinds of means in order to get political and economic stakes and cultural advantages of public opinion. Although dirty, yet it is a wake-up call for some big countries with profound heritages to realize the cultural game.

Dialectically, in the tide of global economic, political, and cultural integration, different countries and nationalities begin to pay more and more attention to the development of local culture. This phenomenon is not only for the unification of culture that makes the habits between different countries and nationalities more similar, but the deeper reason is that the unification makes the gap between the existing national cultural content and foreign culture greater. In other words, in 
the cultural game, the foreign culture is likely to be homogenized, and also likely to be spread under the promotion of the cultural game and diversity and are more likely to make the native culture attributes more diverse.

Cultural integration reveals that human society is beginning to move toward its glory. It takes the global sharing as its supreme goal, game strategies as the method of survival of the fittest and the common morality and values as action rules. The manifestation of the logic guidelines of the strategies in the world culture game is that globalization determines that each culture does not have relatively independent social space and only the optimal culture can be shared which is always in a state of spreading, absorbing, adjustment and modification, the essence of which is that different pursuits of values and action principles are constantly colliding, exchanging and merging with each other, gradually getting mutual recognition and reducing their differences.

Pierre Bourdieu, the famous French socialist, who proposed the "field theory" thinks that cultural globalization's final result is that cultures of different countries will break the limitation of their inherent field and find a way to sustainable development. In this way is achieved cultural unification through the game between cultures of different countries and nationalities. And how many benefits a culture obtains depend on how much it wins in the game.

\section{The Advantages of THE ChINESE ART Form OF TANG AND SONG DYNASTIES IN THE GAME}

Culture is a record of a country, a nation and even the society as a whole, and the only scale to locate the track of the development in our universe that is measured by geography and time. Geographical space generated different cultures of human society and time enlarged the gap between them, which reveals the track of the development of human society that constitutes the whole of human history today. And the new values of every period of history is actually a game between different cultures, which narrows the gap between different cultures caused by space and time.

China, composed of 56 nationalities, is a great country with a written history of more than 3000 years. During this long period of time, our predecessors created the outstanding Chinese civilization, of which the art culture of the Tang and Song dynasties is so brilliant that it cannot be forgotten and replaced.

The Tang dynasty(618 - 907 AD)is one of the dynasties that are united for the longest time and the most prosperous. In the Tang dynasty, the culture reputation then was spread overseas and various types of art form were exchanged between countries in South Asia, west Asia and Europe. The Tang culture is inclusive, relatively open, diverse, and imposing. It absorbed the merits of cultures of different nations and religions. After years of its development and propaganda, the Tang culture became one of the most advanced international cultures at that time, making the peripheral countries take the initiative to exchange and blend with it. In the first half of the Tang dynasty, an important period in which China exported its culture and technologies, all social levels were on a rising stage. In this period, social morality was inclusive, which provided an unprecedented open environment for the surrounding countries for communication and merging. In the mid-and late period of the Tang dynasty, science and technology, culture and art were prosperous and diverse. At that time the surrounding subordinate countries such as Silla, Korea, Baekje, Bohai Kingdom and Japan were greatly influenced by the Tang culture in political systems and social cultures, which exerted a profound impact on their histories and cultures in nearly one thousand years hereafter. From the point of view of today's game theory, it is easy to draw a conclusion that a country with relatively backward culture couldn't resist the huge advantages of the advanced Tang culture and thus was enormously influenced on various social levels, which made all walks of society of the surrounding countries show their fierce adoration for the Tang dynasty and its culture. From another angle of analysis, it can be said that the impact caused by the cultural invasion, to some extent, led to the decline and even extinction of the local cultures of some surrounding countries.

The Song dynasty (960-1279AD), the one after Tang, is the most prosperous historical period in economy, culture, art and science innovation. In this dynasty, the GDP accounted for $60 \%$ of that of the whole world, the first among all dynasties in Chinese history. This period, another peak in the history of the development of Chinese culture, saw the rapid development of science and technology and political transparency and honesty. So the cultures of Tang and Song dynasties are equally important. The culture of the Song dynasty developed based on that of the preceding dynasty, but the unique "Song Culture" is relatively closed, introversive, elegant, exquisite and plump, standing shoulder to shoulder with the "Tang Culture". Today, through the analysis of the "Song Culture" from the perspective of cultural causes, it is easy to draw this conclusion that in the Song dynasty the Confucianism was basically established, ethnic composition relatively single and cultural exchange was becoming more and more conservative because of the perennial wars and battles. In the Song dynasty, in spite of the advanced foreign communication, the academics then could not be separated from the scope of the Chinese native culture, which was determined by the attribute of the "Song Culture". The cultural cause was almost at a standstill in absorbing foreign cultures until the Southern Song perished, which was an obvious phenomenon after the establishment of the Chinese native culture. From another perspective, we can not deny the uniqueness of the Song culture, a main component of today's Chinese culture. As to the value of the Song culture, the modern scholar Chen Yange said in the preface of Deng Guangming's Research on the Officials in the Song Dynasty that after thousands of years of its evolution, the Chinese culture 
reached its climax in the Song dynasty. Obviously, the Song culture has been universally regarded as a milestone in the development of the Chinese culture. The advantages of the culture of the Tang and Song dynasties derived from the combined causes such as the social economy, politics and people's livelihood are mainly expressed in poetry, music, paintings and porcelain. These art forms, at any time, are the main exported ones in the world culture game.

\section{The Role of the Traditional Chinese ART CUlture In THE GAME}

Human society is stumbling forward through different games. In the process of the Chinese and western art and culture integrating into the world civilization, there indeed exist recognized cultural forms by all countries and nations. And how to find and sum up the forms is an important measure in their adopted strategies in the game.

So when looking for these highly recognized forms of culture, we should compare and analyze the differences between the Chinese and western art culture. Firstly, the difference lies in "conforming to nature" and "conquering nature". The traditional Chinese art culture was established based on its emphasis on its harmonious relationship with nature, while the western art culture lays more emphasis on the conquest and transformation of nature and individual ideals. According to the oriental culture, the art development is a process of the exchange and integration between matter and spirit, which shows their harmony. In terms of art, the western culture pays more attention to art form and the practical value it brings to people. From the point of view of game theory, the Chinese and western culture has their own strong points and are hard to decide which is more important. However, which is better in the game will be finally figured out through varied strategies. So which strategy will be used in the game has become a key research direction for eastern and western game scholars. Most domestic scholars with their researches focused on the game strategies think that if the decision that which cultural strategy should be used cannot be made in a short time, then the present one should be used in order to make the opponents change their strategies, which can help achieve the aim of the game. Thus, the chances to win will be increased. So the purpose of the existing ideas is to identify the game state in the "perfect equilibrium theory" of shaking hands proposed by the German scholar Reinhard Selten, that is, when in confrontation, the obvious advantage of one culture will not be used as the offensive strategy, but as an announcement to its opponent that the rewards brought by the future victory will be enormous, which can cause the opponent to ignore the possible failure the advantage may bring. Compared with the possible rewards brought by the advantage used as the offensive strategy, the measure will make the rewards be more enormous. Therefore, a conclusion can be drawn that the the shown advantage can bring more rewards that the used advantage in the "perfect equilibrium theory" of shaking hands. In other words, this means that in confrontation period in the game, one culture gets the most benefits without using its advantage, making its opponent ignorant of the possible failure the advantage may bring, that is, to increase the chances for the opponent' responding strategy to fail in the context of benefits belonging to each "player". The best way to gain the initiative in the "perfect equilibrium theory" of shaking hands for one culture is to show its advantage to prevent its opponent from making any responding strategy in a short time so that it can not only reach its aim, but also get some rewards. The art culture of the Tang and Song dynasties exactly inherits and shows the essence of the traditional Chinese culture, the roles of which cannot be replaced in the "perfect equilibrium theory" of shaking hands.

\section{CONCLUSION}

Art, a cultural attribute, is a product of human material and spiritual civilization. Different artistic styles profoundly show different cultural attributes of a region or a nation and regional backgrounds. Cultures all over the world are different in art form, humanity ideas, and developmental origins that are due to different space and time in which they are generated. In other words, the varied cultural attributes of different regions or nations are determined by the regional differences. Today, human culture with a history of one thousand years has been updated by the highly-developed science and technology, the regional causes resulting in cultural differences staying on the verge of collapse. And the world cultural integration has become an irresistible trend. Then there comes an important topic that how can the cultural system of one country or nation can be respected by others in the "global village" in the world cultural game.

By studying the art form of the Tang and Song dynasties as an important part in the world cultural game, its role in the development of the world history of culture, thinking, and folk customs can be revealed. Then its huge influence on the status of today's Chinese in the world culture can be displayed so as to obtain cultural advantage and benefits in politics,economy, and people's livelihood. All these reveal the aim and practical value of the research on the art form of the Tang and Song dynasties in the world cultural game.

\section{ACKNOWLEDGMENT}

№1. Education Department of Henan Province in 2013 focused on science and technology research projects, airport ground crew helmets and UI design research interaction, №.14 B590001

№2. 2014 Zhengzhou City, the general scientific and technological research projects planned, modeling and design research practice small 3D printer product family, №. N2014G0025

\section{REFERENCES}

[1] Paul Jakov Smith \& Richard von Glahn, The Song-Yuan-Ming transition in Chinese history, Harvard University Asia Center.Distributed by Harvard University Press.2003.11

[2] Han yi: the Tang and Song Dynasties thought and culture history research. Xinjiang philosophy and social science.2011.3

[3] Luo Yinan: The patterns and changes -- changes of Tang and Song Dynasties view in historiography.Research on cultural Chinese.2003.2 
[4] Wang Kuiqing: Cultural game and cultural integration.Changbai journal.2005.5

[5] Zhang Chu: Game trick.Chongqing press.2011.3 